\title{
STATEGI PENGELOLAAN ZAKAT PRODUKTIF BADAN AMIL ZAKAT KABUPATEN KARANGANYAR DALAM RANGKA PENGENTASAN KEMISKINAN
}

\author{
Andi Triyawan \\ Khairunnisa Sana Shafiyyah
}

\begin{abstract}
:
The poverty in Indonesia is the long-term problem which it has not been solved by the government. The number of poor people that recorded by Central Bureau of Statistics in Karanganyar is 108.461 inhabitants (2014). Islam has a high attention to take the poverty and the backwardness down from the poor man, because the poverty in Islam is the big danger for the people and not a few people who fall civilization only because of poverty. For solving this problem, Islam has the exact alternative. Islamic Economic system has two instruments which can solve the long-term poverty problem in Indonesia they are zakat and cash waqf. Zakat is the one of economics' element and the pillars of Islam which must be implemented by every Moslem. Zakat is already widely distributed to several mustahik such as an indigent, poor, orphan, street children and other. And we can see also that zakat has been distributed to fund the development of infrastructure such us mosque, employment and other. But, most of distributed zakat is the consumptive zakat. Whereas the effective zakat for economic growth is the productive zakat which educates mustahik to attempt and to manage zakat fund until he can be muzakki later. From the background, the writer's research is about the productive zakat management strategy in order towards poverty reduction. And the purpose of it is to know about the productive zakat management strategy in BAZNAS Karanganyar and its role for poverty reduction. The method of this research is descriptive qualitative method that reveals the problem or the reality as what happened until it can reveal the fact and the real image of the object. And to get the data, the writer use interview technique and written records about the productive zakat in BAZNAS Karanganyar. For the data analysis, the writer use the technique of data reduction, data display and inference aboutthe review on the research results. The research's result is the productive zakat management strategy in BAZNAS Karanganyar has two categories, collection strategy and distribution strategy. The collection strategy applicated with payroll deduction of the moslem government employees in SKPD Karanganyar amount 2,5\%, shuttle service zakat and formation the unit of zakat collection in several villages and mosques. And the distribution strategy applicated in "Karanganyar Makmur" program which includes the course of computer and automotive; the training of bag tailor industry; the goat livestock development in several villages in Karanganyar; financing sellers and small businessmen; the cow livestock development; and the other about the sharia business unit and Baitul Maal in several subdistricts. And from the application programs in BAZNAS Karanganyar, these programs are intended to improve the standard of living mustahik from economic, ability and moral side so that poverty can be overcome by any cause. From the result of research, for increasing the potential of the productive zakat, BAZNAS Karanganyar ought to be careful and to objectify the programs about the productive zakat. And for mustahik ought to keep attention and to increase zakat funds' productivity until the poverty reduction with the productive zakat can be embodied.
\end{abstract}

Keywords: Productive Zakat, BAZ, Poverty Alleviation, Management Strategy

\section{PENDAHULUAN}

Masalah kemiskinan di Indonesia

merupakan masalah berkepanjangan

yang mana pemerintah masih belum

mampu dalam pemecahannya. Jumlah

orang miskin yang diambil dari Badan
Pusat Statistik (BPS) Karanganyar mencapai 108.461 jiwa (2014).' Maka data ini menunjukkan bahwa masyarakat

\footnotetext{
1 http://karanganyarkab.bps.go.id
} 
Triyawan, et al/Jurnal Ekonomi Syariah Teori dan Terapan Vol. 6 No. 6 Juni 2019: 1304-1316; STATEGI PENGELOLAAN ZAKAT PRODUKTIF BADAN AMIL ZAKAT KABUPATEN KARANGANYAR DALAM RANGKA PENGENTASAN KEMISKINAN

Indonesia belum sepenuhnya bebas dari masalah kemiskinan.

Kemiskinan merupakan masalah besar dan sejak lama telah ada, dan hal ini menjadi kenyataan di dalam kehidupan. Islam memandang bahwa masalah kemiskinan adalah masalah tidak tepenuhinya kebutuhan-kebutuhan primer secara menyeluruh, yaitu masalah sandang, pangan dan papan.2Dalam menangani masalah kemiskinan tersebut, Islammemiliki alternatif yang tepat. Sistem perekonomian Islam memiliki dua instrumen yang dapat menangani masalah kemiskinan yang berkelanjutan di Indonesia yaitu zakat dan wakaf uang. ${ }^{3}$

Zakat sudah banyak didistribusikan ke beberapa mustahik, seperti fakir, miskin, anak yatim dan jalanan, dan sebagainya. Juga dapat dilihat, zakat digunakan untuk membiayai pembangunan beberapa saraa, seperti masjid, lapangan kerja, dan lain sebagainya. Akan tetapi, kebanyakan dari zakat yang disalurkan tersebut berbentuk konsumtif. Sedangkan zakat yang paling efektif dalam pertumbuhan ekonomi umat adalah zakat produktif.

Banyak dari lembaga amil zakat telah memasukkan model zakat produktif sebagai salah satu pengelolaan zakat yang menjanjikan. Akan tetapi, banyak dari beberapa lembaga masih

2 Amalia, Kasyful Mahali, Jurnal-Potensi dan Peranan Zakat dalam Mengentaskan Kemiskinan di Kota Medan- hlm. 1, Desember 2012

3 Departemen Agama, Pedoman Zakat, Jakarta: Proyek Pembinaan Zakat dan Wakaf, 1993, hlm.15. mendistribusikan zakat dalam bentuk konsumtif sehingga masih ada beberapa pertanyaan, apakah program zakat produktif tersebut telah berjalan atau masih terhambat oleh beberapa kendala atau ada hal lain yang masih belum diketahui.

\section{TINJAUAN PUSTAKA}

\section{Zakat Produktif}

Ditinjau dari segi bahasa, menurut lisan orang Arab, kata zakat merupakan kata dasar (masdar) dari zakka-yuzakki yang berarti suci, berkah, tumbuh, dan terpuji, yang semua arti ini digunakan dalam menerjemahkan Al-Qur'an dan Hadits. ${ }^{4}$

Menurut terminologi syariat (istilah), zakat adalah nama bagi sejumlah harta tertentu yang telah mencapai syarat tertentu yang diwajibkan oleh Allah untuk dikeluarkan dan diberikan kepada yang berhak menerimanya dengan persyaratan tertentu pula. 5 Dalam AlQur'an Allah berfirman, "Sesungguhnya penolong kamu hanyalah Allah, RasulNya, dan orang-orang yang beriman, yang mendirikan shalat dan menunaikan zakat, seraya mereka tunduk (kepada Allah)."6

Sedangkan dalam Hadits Rasulullaah SAW bersabda:

4Muhammad dan Ridwan Mas'ud (2005). Zakat dan Kemiskinan Instrumen Pemberdayaan Ekonomi Umat. (Yogyakarta: UII Press), hlm. 33-34. 5DikutipolehK.H.DidinHafidhhuddin(2002)d alambuku,ZakatDalamPerekonomian Modern. (Jakarta: Gema Insani), hlm. 7.

${ }^{6}$ Q.S. Al-Maa'idah: 55 
Triyawan, et al/Jurnal Ekonomi Syariah Teori dan Terapan Vol. 6 No. 6 Juni 2019: 1304-1316; STATEGI PENGELOLAAN ZAKAT PRODUKTIF BADAN AMIL ZAKAT KABUPATEN KARANGANYAR DALAM RANGKA PENGENTASAN KEMISKINAN

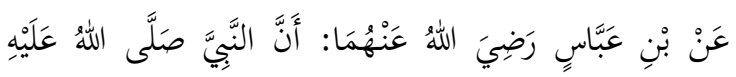

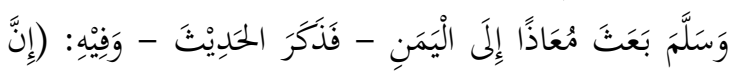

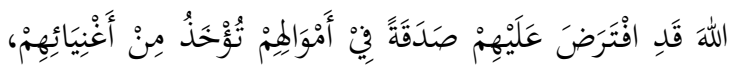

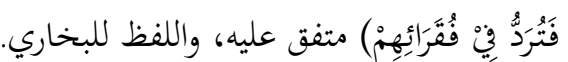
Kaitan antara makna bahasa dan istilah ini berkaitan erat sekali, yaitu bahwa setiap harta yang sudah dikeluarkan zakatnya akan menjadi suci, bersih, baik, berkah, tumbuh dan berkembang. Dalam penggunaannya, selain untuk kekayaan, tumbuh dan suci disifatkan untuk jiwa orang yang menunaikan zakat. Maksudnya, zakat itu akan mensucikan orang yang mengeluarkannya dan menumbuhkan pahalanya.

Dalam istilah ekonomi, zakat merupakan tindakan pemindahan kekayaan dari golongan kaya (muzakki) kepada golongan tidak punya (mustahiq). Ada delapan golongan yang termasuk dalam mustahiq, yaitu:

1. Orang fakir.

2. Orang miskin.

3. Pengurus zakat (amil).

4. Muallaf.

5. Budak.

6. Orang berhutang.

7. Pada jalan Allah (fi sabilillah), yaitu untuk keperluan pertahanan Islam dan kaum muslimin.

8. Orang yang sedang dalam perjalanan (ibnu sabil) yang bukan maksiat dan mengalami kesengsaraan dalam perjalanannya. $^{7}$

7Q.S. At-Taubah: 60
Sedangkan yang dimaksud dengan zakat produktif adalah zakat yang diberikan kepada mustahiq sebagai modal untuk menjalankan suatu kegiatan ekonomi yaitu untuk menumbuhkembangkan tingkat ekonomi dan potensi produktivitas mustahiq. ${ }^{8}$

\section{Tujuan dan Hikmah Zakat}

Setiap segala ajaran agama Islam pasti mempunyai sebuah tujuan, di antara tujuan-tujuan zakat adalah memecahkan permasalahan yang dihadapi oleh mustahik khususnya orangorang fakir dan miskin, membina tali silaturrahim dan solidaritas sesama umat manusia, menghilangkan sifat bakhil bagi pemilik harta dan modal yang disebabkan oleh penumpukan harta kekayaan perseorangan, serta mencegah jurang pemisah antara orang kaya dan miskin sehingga mereka mengetahui hak dan kewajiban dari masing-masing pihak.

Dalam melaksanakan zakat sebenaryna banyak sekali hikmah dan makna yang terkandung di dalamnya. Menurut Al-Ghazali9 ada tiga makna yang dapat dipetik dalam melaksanakan zakat, yaitu pengucapan dua kalimat syahadat, mensucikan diri dari sifat kebakhilan, dan mensyukuri nikmat Allah yang telah diberikan.

\section{Harta yang Wajib Dizakati}

8AbduracchmanQadir(2001).ZakatDalam DimensiMahdahdanSosial.Cet.2 (Jakarta: PT. Raja GrafindoPersada), hlm. 165.

9 Al-Ghazali (1994) Rahasia Puasa dan Zakat-Terjemahan oleh Muhammad AlBaqir-(Bandung: Karisma) hlm. 66 
Triyawan, et al/Jurnal Ekonomi Syariah Teori dan Terapan Vol. 6 No. 6 Juni 2019: 1304-1316; STATEGI PENGELOLAAN ZAKAT PRODUKTIF BADAN AMIL ZAKAT KABUPATEN KARANGANYAR DALAM RANGKA PENGENTASAN KEMISKINAN

Pada hakikatnya, semua yang dihasilkan dari usaha seorang muslim, apapun sumbernya, pasti ada hak dari sebagian harta tersebut yang harus diberikan kepada kaum yang membutuhkan, dalam arti harta itu harus dikeluarkan zakatnya. Tetapi disisi lain juga ada harta yangtidak terkena atau wajib zakat. Pada umumnya harta yang harus dikelurkan zakatnya ada lima jenis, yaitu emas dan perak, barang tambang dan barang temuan, harta perdagangan, tanaman dan buah- buahan, dan binatang ternak yaitu unta, sapi dan kambing. ${ }^{10}$

\section{Distribusi Zakat}

Distribusi zakat, menurut mazhab Syafi'i tidak membolehkan pembayaran zakat hanya dalam satu kelompok saja karena berpegang teguh pada ayat al Qur'an surat at Taubah ayat 60. Sedangkan menurut Hanafi, Maliki, dan Hanbali seperti halnya Umar bin Khattab, membolehkan pembagian zakat hanya kepada satu kelompok saja, bahkan mazhab Maliki menyatakan bahwa memberikan zakat kepada orang yang sangat membutuhkan dibandingkan kelompok yang lainnya adalah sunah."

Berikut akan sedikit dijelaskan mengenai siapa saja delapan kelompok yang dimaksud mendapatkan zakat:

a. Orang fakir (fuqara')

10 Wahbah Az Zuhayly (1995) Zakat Kajian Berbagai Mazhab (Bandung: PT Remaja Rosda Karya) hlm. 126

11Wahab Az Zuhayly (1995) Op. Cit., hlm. 279 b. Orang miskin (masakin)

c. Panitia zakat (amil)

d. Mu'allaf yang perlu ditundukkan hatinya

e. Para budak

f. Orang yang memiliki hutang

g. Fi Sabilillah

h. Ibnu sabil

Di samping penjelasan delapan asnaf tersebut di atas, ada beberapa ketentuan khusus sebagai berikut:

a. Pengaturan bagi fakir miskin

b. Zakat kepada sanak kerabat

C. Zakat kepada pencari ilmu

d. Zakat kepada suami yang fakir

e. Zakat kepada orang saleh ${ }^{12}$

Selain orang-orang yang berhak menerima zakat, ada pula beberapa orang atau kelompok yang tidak boleh mendapat pembagian zakat, yaitu :

a. Keturunan Nabi (Bani Hasyim dan Bani Muthalib)

b. Keluarga muzakki yang meliputi anak dan istri.

c. Orang Kafir.

Pengelolaan Zakat di Lembaga Zakat

Orientasi pengelolaan zakat secara produktif harus dipahami bersamasama secara menyeluruh oleh semua masyarakat (muzakki, amil dan mustahiq). Masyarakat harus memahami tujuan dari pengelolaan zakat produktif yaitu untuk kesejahteraan masyarakat, seperti yang

12Departemen Agama (1996) Pedoman Zakat 9 Seri (Jakarta: Departemen Agama)hlm. 126-129 
Triyawan, et al/Jurnal Ekonomi Syariah Teori dan Terapan Vol. 6 No. 6 Juni 2019: 1304-1316; STATEGI PENGELOLAAN ZAKAT PRODUKTIF BADAN AMIL ZAKAT KABUPATEN KARANGANYAR DALAM RANGKA PENGENTASAN KEMISKINAN

disebutkan dalam pasal 3 UU nomor 23 tahun 2011 bahwa pengelolaan zakat bertujuan:

a. Meningkatkan efektivitas dan efisiensi pelayanan dalam pengelolaan zakat.

b. Meningkatkan manfaat zakat untuk mewujudkan kesejahteraan masyarakat dan penanggulangan kemiskinan.

Untuk mengoptimalkan pengelolaan zakat yang produktif, dewasa ini muncul konsepsi kontemporer tentang permasalahan zakat yang telahjauh melampui pendapat-pendapat hukum klasik, terutama menyangkut tiga hal pokok, yaitu:

a. Pengembangan Obyek Zakat

b. Kelembagaan Zakat

Untuk membentuk sebuah lembaga atau panitia amil zakat yang berkualitas paling tidak ada tiga hal yang harus dipenuhi:

1) Amanah

2) Fatonah

3) Transparan

c. Pendayagunaan Zakat

Secara umum terdapat dua pendapat masalah pendayagunaan dana zakat. Pertama, bahwa zakat lebih bersifat konsumtif dan disalurkan secara langsung kepada para mustahiq untuk kepentingan konsumtif. Kedua, bahwa pendayagunaan dana zakat mengedepankan aspek sosial ekonomi yang luas tidak sekedar konsumtif. Untuk mencermati hal ini, perlu dibedakan antara zakat fitrah dan zakat mal. Meski keduanya memiliki nilai ibadah (hablun minAllah) namun ada perbedaan antara keduanya. Zakat fitrah yang dimaknai sebagai kewajiban bagi setiap muslim tanpa terkecuali untuk mensucikan diri, dan sifat dari zakat fitrah untuk kebutuhan konsumtif. Sedangkan zakat mal yang bertujuan untuk mensucikan harta maka sifat dari zakat ini untuk kepentingan produktif, untuk menyokong pengembangan harta para mustahiq terutama fakir miskin.

\section{Kemiskinan}

Kemiskinan adalah keadaan penghidupan di mana orang tidak mampu memenuhi kebutuhan dasar. Zakiyah Darajat mendefinisikan kemiskinan bahwa orang yang tidak cukup penghidupannya dan dalam kekurangan. Bambang Sudibyo mengukur ketetapan miskin dengan memakai standar nisab zakat. ${ }^{3}$ Akan tetapi yang terjadi di dalam masyarakat tidak jarang adanya perdebatan dalam kategorisasi seseorang dikatakan miskin, hal tersebut karena masyarakat memandang bahwa kurang atau tidaknya pemenuhan sehari-hari itu bersifat relatif.Kebutuhan pokok dinyatakan secara kuantutatif (bentuk vang) berdasarkan harga tiap

\footnotetext{
13Ridwan Mas'ud dan Muhammad (2005) Op. Cit., Ridwan Mas'ud dan Muhammad (2005) Zakat dan Kemiskinan Instrumen Pemberdayaan Ekonomi Umat (Yogyakarta: UII Press) hlm. 70
} 
Triyawan, et al/Jurnal Ekonomi Syariah Teori dan Terapan Vol. 6 No. 6 Juni 2019: 1304-1316; STATEGI PENGELOLAAN ZAKAT PRODUKTIF BADAN AMIL ZAKAT KABUPATEN KARANGANYAR DALAM RANGKA PENGENTASAN KEMISKINAN

tahunnya. ${ }^{14}$ Ukuran tersebut di atas menurut hemat penulis cukup untuk dijadikan landasan penentuan kategorisasi miskin karena sudah mencakup kebutuhan-kebutuhan dasar seseorang dalam kehidupan sehari-hari.

Jika ditinjau dari pendapatan, kemiskinan ada dua macam yaitu kemiskinan relatif dan absolut. Kemiskinan relatif adalah kemiskinan yang dilihat antara satu tingkatan pendapatan dengan tingkat pendapatan lainnya, sebagai contohnya seseorang dalam kelompok masyarakat tertentu dapat digolongkan kaya akan tetapi dalam kelompok lain dapat digolongkan miskin. Sedangkan kemiskinan absolut adalah suatu keadaan kemiskinan yang ditentukan terlebih dahulu menetapkan garis tingkat pendapatan di atas tingkat pendapatan minimum tersebut dikategorikan bukan orang miskin.

Kemiskinan jika ditinjau dari penyebabnya ada dua macam yaitu sebab mental (kultural) dan struktural. Kemiskinan yang disebabkan oleh kultural yaitu kemiskinan yang disebabkan oleh budaya seperti malas, boros, dan lainnya. Sedangkan Kemiskinan yang disebabkan struktural adalah kemiskinan yang disebabkan oleh sistem pembangunan yang tidak adil dandiakibatkan oleh faktor-faktor ulah rekayasa manusia.

14Ridwan Mas'ud dan Muhammad (2005) Op. Cit., hlm. 71
Secara umum ada beberapa faktor penyebab terjadinya kemiskinan khususnya di pedesaan, di antaranya adalah:

a. Kurangnya pengembangan SDM

b. Adanya struktur yang menghambat pengembangan ekonomi rakyat pedesaan

c. Ketidakberuntungan kelompok masyarakat miskin pedesaan

d. Ketimpangan distribusi pembangunan antara Kota dan Desa.

Kemiskinan, dalam Islam menjadi perhatian serius. Hal tersebut terbukti dengan banyaknya ayat-ayat al qur'an yang memerintahkan untuk memberikan makanan kepada orang-orang yang kelaparan dan saling mengingatkan untuk menolong fakir miskin. Begitu pentingnya menolong orang orang miskin, sehingga Allah menyatakan sebagai pendusta agamaorang yang tidak mau memberi makan orang miskin dengan firman-Nya:

Artinya: "Tahukah kamu (orang) yang mendustakan agama? Itulah orang yang menghardik anak yatim, dan tidak menganjurkan memberi makan orang miskin"15

\section{HASIL DAN PEMBAHASAN}

Program Kegiatan di BAZNAS Karanganyar

Berdasarkan hasil Rapat Pengurus BAZNAS Kabupaten Karanganyar, program kerja tahun 2011 dirumuskan sebagai berikut:

a. Membangun kepercayaan masyarakat kepada Amil

${ }^{15}$ Q.S. Al-Maa'un : 1-3 
Triyawan, et al/Jurnal Ekonomi Syariah Teori dan Terapan Vol. 6 No. 6 Juni 2019: 1304-1316; STATEGI PENGELOLAAN ZAKAT PRODUKTIF BADAN AMIL ZAKAT KABUPATEN KARANGANYAR DALAM RANGKA PENGENTASAN KEMISKINAN

b. Mengoptimalkan tugas Amil sesuai surat keputusan Bupati

c. Menambah jumlah pemasukan ZIS mulai bulan April 2011

d. Mentashorufkan/mendayagunakan hasil pengumpulan ZIS sesuai dengan ketentuan

e. Memfungsikan dan menertibkan sekretariat Kantor BAZNAS Kabupaten Karanganyar

Langkah-langkah kegiatannya diaplikasikan dan dirangkum pada seksi pengumpulan, seksi pendistribusian, seksi pendayagunaan, seksi pengembangan dan sekretariat.

\section{Strategi Pengelolaan Zakat di BAZNAS}

Karanganyar

Pengelolaan zakat produktif di BAZNAS Karanganyar terbagi menjadi dua strategi yaitu strategi pengumpulan dan pendistribusian.

\section{a. Pengumpulan Zakat}

Zakat di BAZNAS Kabupaten Karanganyar merupakan zakat yang didapatkan dari berbagai pihak yang berkaitan. Pengumpulan zakat dilakukan secara proaktif yaitu pihak BAZNAS yang mewajibkan dan mencanangkan program-program zakat kepada masyarakat, pegawai negeri dan lain sebagainya. Program pengumpulan zakat disatukan dengan pengumpulan infak dan shadaqah. Maka program pengumpulan ZIS (Zakat, Infak dan Shadaqah) dilaksanakan oleh beberapa pihak, yaitu: a. Bupati bertanggung jawab atas Pengumpulan Amal di Tingkat Kabupaten

b. Camat bertanggungjawab atas Pengumpulan Amal di Tingkat Kecamatan

c. Kepala Desa/ Kelurahan bertanggung jawab atas Pengumpulan Amal Tingkat Desa/ Kelurahan

d. Kepala SKPD/ Unit Kerja bertanggungjawab atas pengumpulan amal dari masingmasing staf/ karyawannya.

e. Pimpinan Perusahaan bertanggungjawab atas pengumpulan amal dari masingmasing staf/ karyawannya.

\section{b. Pendistribusian Zakat}

Program - program pendistribusian zakat yang ada di BAZNAS Karanganyar adalah sebagai berikut:

a. Karanganyar Peduli (Kemanusiaan), yang meliputi:

1) Bantuan Fakir Miskin

2) Gharim (orang yang berhutang)

3) Bantuan Sosial

4) Bantuan Bedah Rumah Fakir Miskin

5) Bantuan Bencana

b. Karanganyar Sehat (Kesehatan), yang meliputi:

1) Pengobatan Poli Gratis

2) Ambulans Gratis

3) Bantuan Operasi Bibir Sumbing

4) Bantuan Operasi Katarak

5) Bantuan Penyembuhan HIV 
6) Bantuan Kesehatan Fakir Miskin

c. Karanganyar Cerdas (Pendidikan), yang meliputi:

1) Bantuan Beasiswa Anak Sekolah dan Mahasiswa

2) Bantuan Sekolah, Madrasah dan Pondok Pesantren

3) Bantuan Sekolah Tilawah

4) Bantuan TPA/TPQ

5) Pelatihan Kursus

6) Pelatihan Da'i dan Khotib

7) Pelatihan Manajemen Masjid

8) Pelatihan Guru TPA/TPQ

d. Karanganyar Makmur (Bantuan Ekonomi)

1) Bantuan Desa Barokah

2) Bantuan Pinjaman Mesin Jahit Tas

3) Bantuan Wirausaha Kecil

4) Modal Usaha

5) Gaduh Ternak Sapi

6) Bantuan Ternak Kambing

7) Bantuan Usaha Mandiri

e. Karanganyar Taqwa (Syiar dan Islam)
1) Bantuan Fisik Tempat Ibadah
2) Bantuan Da'i Mubaligh
3) Bantuan TPQ
4) Bantuan Kegiatan Keagamaan
5) Sertfikasi Wakaf
6) Sosialisasi Halal
7) Siaran Dakwah PHBI
8) Khataman
9) Kaligrafi Jalan Raya
10) Jadwal Sholat dan Puasa
11) Bantuan Jum'at Keliling
12) Bantuan Subuh Keliling

13) Cetak Buletin dan Kalender BAZNAS

14) Kegiatan MTQ

15) Konsultasi ZIS Solo Pos

16) Cetak Khutbah Jum'at

17) Pengadaan Al-Qur'an dan Iqro'

18) Bantuan UPZ Takmir Masjid

19) Sosialisasi UPZ Desa/Kelurahan ${ }^{16}$ Maka, dengan program-program yang telah dibentuk oleh BAZNAS Kabupaten Karanganyar tersebut, diharapkan zakat dapat menyeluruh pada seluruh lapisan hidup di Kabupaten Karanganyar.

\section{Pengelolaan Zakat Produktif di BAZNAS Karanganyar}

Seperti yang sudah diketahui bahwa zakat produktif adalah zakat yang dialokasikan untuk pengembangan usaha produktif yang dimaksudkan untuk mendidik para mustahik demi kesejahteraan hidupnya. Dengan tujuan ini, BAZNAS Kabupaten Karanganyar berusaha untuk merealisasikan tujuan ini dengan beberapa strategi efektif untuk mengurangi jumlah kemiskinan, yaitu:

a. Pengumpulan Zakat Produktif di BAZNAS Kabupaten Karanganyar

Pengumpulan zakat produktif di BAZNAS Kabupaten Karanganyar tidak dikhususkan dalam kriteria zakat produktif saja, tetapi bersamaan dengan pengumpulan zakat secara keseluruhan, juga dalam bentuk infak dan shadaqah.

\footnotetext{
16 www.baznaskaranganyar.com
} 
Triyawan, et al/Jurnal Ekonomi Syariah Teori dan Terapan Vol. 6 No. 6 Juni 2019: 1304-1316; STATEGI PENGELOLAAN ZAKAT PRODUKTIF BADAN AMIL ZAKAT KABUPATEN KARANGANYAR DALAM RANGKA PENGENTASAN KEMISKINAN

Selain dari sosialisasi di desa-desa seperti yang sudah disebutkan, strategi pengumpulan lebih ditekankan kepada para PNS yang ada di SKPD Kabupaten Karanganyar17.

Sedangkan dalam mengenalkan BAZNAS kepada masyarakat umum, selain melalui sosialisasi, juga melalui pengadaan kegiatan-kegiatan yang bertujuan untuk menunjukkan kiprah BAZNAS Kabupaten Karanganyar dan memasang profil BAZNAS Kabupaten Karanganyar di rubik "Solopos", 18 sehingga pengetahuan tentang BAZNAS Kabupaten Karanganyar tidak terbatas pada masyarakat Kabupaten Karanganyar, melainkan masyarakat se-Solo Raya.

b. Pendistribusian Zakat Produktif di BAZNAS Kabupaten Karanganyar

Dari lima program yang merupakan rangkuman dari program pendistribusian zakat, zakat untuk usaha produktif dialokasikan kepada mustahik dalam program Karanganyar Makmur yang mana zakat diberikan dengan tujuan meningkatkan taraf perekonomian.

Strategi pendistribusian zakat produktif di BAZNAS Kabupaten Karanganyar diaplikasikan dengan berbagai kegiatan, yaitu:

1) Kursus-kursus

17 Transkrip Wawancara,

01/WWCR/BAZNAS/IV/2016

18 Transkrip Wawancara, Op.Cit.
Dalam pengadaan kursus, BAZNAS Kabupaten Karanganyar bekerjasama dengan beberapa lembaga, di antaranya adalah Dinas Sosial yaitu BLK (Balai Latihan Kerja) Karanganyar yang terdapat didalamnya kursus menjahit, komputer, otomotif dan juga dengan Universitas Negeri Sebelas Maret (UNS).

2) Pelatihan dalam Industri Jahit

Selain kursus-kursus, BAZNAS

Kabupaten Karanganyar juga mengadakan pelatihan menjahit industri tasdan order didapatkan dari para penjahit.

3) Ternak Kambing

Zakat untuk usaha produktif juga disalurkan dalam bentuk ternak kambing dan bekerjasama dengan Pemerintah Desa. Jadi, BAZNAS menyediakan biaya pengembangan usaha produktif tersebut, Pemerintah Desa menjadi mitra kerja, dan BAZNAS yang mengevaluasi tentang pengembangan usaha produktif tersebut dengan cara survey dadakan. 19

4) Pembiayaan Para Pedagang atau Pengusaha Kecil/PKL (Pedagang Kaki Lima)

Dalam pembiayaan para pedagang atau pengusaha kecil yang mayoritas dari PKL (Pedagang Kaki Lima) di Kabupaten Karanganyar. Biaya diberikan kepada para pedagang dan pengusaha yang

19 Transkip Wawancara, Op.Cit. 
Triyawan, et al/Jurnal Ekonomi Syariah Teori dan Terapan Vol. 6 No. 6 Juni 2019: 1304-1316; STATEGI PENGELOLAAN ZAKAT PRODUKTIF BADAN AMIL ZAKAT KABUPATEN KARANGANYAR DALAM RANGKA PENGENTASAN KEMISKINAN

menjadi anggota binaan BAZNAS Karanganyar berupa dana sebesar Rp 1.000.000,-.

5) Bantuan Gaduh Ternak Sapi

Program ini diaplikasikan dengan cara pengadaan sapi dan penyerahan kepada mustahik untuk dikelola sehingga dapat menjadi salah satu usaha yang produktif.

6) Lain-lain

Selain program-program di atas, BAZNAS Kabupaten Karangnyar juga berperan dalam pendirian baitul maal dan unit usaha syariah.

Dari program-program dan strategi yang telah dijalankan oleh BAZNAS Kabupaten Karanganyar dengan kerjasama pihak-pihak lain, ada beberapa kendala yang dialami oleh BAZNAS Kabupaten Karanganyar yaitu kurangnya tenaga SDM (Sumber Daya Manusia) dalam menjalankan beberapa kegiatan yang ada dalam program kerja BAZNAS Kabupaten Karanganyar. Kendala tersebut diakibatkan dari sulitnya mensinkronkan jadwal antar pengurus. ${ }^{20}$ Dan BAZNAS Kabupaten Karanganyar memiliki solusi untuk mengatasi kendala tersebut yaitu menjalin kerjasama dengan berbagai pihak sehingga masalah SDM dapat teratasi dengan baik.

Pengelolaan Zakat Produktif di BAZNAS Karanganyar dalam Rangka Pengentasan Kemiskinan

20 Transkip Wawancara, 001/WWCR/..., Op.Cit.
Seperti yang telah dijelaskan di atas bahwasanya pengumpulan zakat produktif di BAZNAS Kabupaten Karanganyar memiliki berbagai cara, dari penjemputan zakat, pembentukan UPZ sampai pada pemotongan gaji pegawai negeri muslim sebesar 2,5\%. Dan strategi program pengumpulan yang sedang digalakkan akhir-akhir ini adalah para pegawai negeri yang terdaftar dalam SKPD Kabupaten Karanganyar yang akhirnya dilakukan dengan cara pemotongan gaji dengan potongan yang telah disebutkan dan dana tersebut langsung masuk ke rekening BAZNAS Kabupaten Karanganyar ${ }^{21}$ dengan asumsi sebagai berikut:

PNS Muslim di Kabupaten Karanganyar \pm 10.000 orang dan tiap-tiap dari mereka membayar zakat $2,5 \%$ dari gaji mereka (dengan rata-rata Rp 25.000,), maka zakat yang terkumpul dari para PNS di Kabupaten Karanganyar adalah: 10.000 orang $\times \operatorname{Rp} 25.000,-\times 12$ bulan $=R p$ 3.000.000.000,-22

Maka dapat disimpulkan bahwa strategi pengumpulan zakat melalui PNS di SKPD Kabupaten Karanganyar memiliki potensi yang tinggi.

\footnotetext{
21 Suara Merdeka, 26 April 2016, 10.36 WIB

22 www.baznaskaranganyar.com
} 


\section{Tabel 1.}

Program Zakat SKPD Kabupaten Karanganyar

\begin{tabular}{|c|c|c|c|c|c|}
\hline NO & PROGRAM & SK I & SK II & SK III & SK IV \\
\hline 1 & PEDULI & $\begin{array}{ll}\mathrm{Rp} & 103.000 .000\end{array}$ & $\begin{array}{ll}\mathrm{Rp} & 187.500 .000\end{array}$ & $\mathrm{Rp} \quad 195.000 .000$ & - \\
\hline 2 & SEHAT & $\begin{array}{ll}\mathrm{Rp} & 76.450 .000\end{array}$ & $\begin{array}{ll}\mathrm{Rp} & 51.950 .000\end{array}$ & Rp $\quad 325.000 .000$ & $\begin{array}{ll}\mathrm{Rp} & 250.000 .000\end{array}$ \\
\hline 3 & CERDAS & $\begin{array}{ll}\mathrm{Rp} & 427.050 .000\end{array}$ & $\begin{array}{ll}\mathrm{Rp} & 320.750 .000\end{array}$ & $\mathrm{Rp} \quad 655.000 .000$ & - \\
\hline 4 & MAKMUR & $\begin{array}{ll}\mathrm{Rp} & 204.500 .000\end{array}$ & $\begin{array}{ll}\mathrm{Rp} & 104.000 .000\end{array}$ & $\mathrm{Rp} \quad 245.000 .000$ & $\mathrm{Rp} \quad 1.950 .000 .000$ \\
\hline 5 & TAQWA & Rp 1.189 .400 .000 & Rp $\quad 985.800 .000$ & Rp $\quad 930.000 .000$ & Rp $\quad 250.000 .000$ \\
\hline & & Rp 2.000.000.000 & Rp 1.650.000.000 & $\operatorname{Rp} 2.350 .000 .000$ & Rp 2.450.000.000 \\
\hline
\end{tabular}

Strategi yang dilakukan oleh pihak

BAZNAS Kabupaten Karanganyar ini terbukti berpotensi tinggi dengan meningkatnya total penghimpunan zakat di lembaga ini. ${ }^{23}$

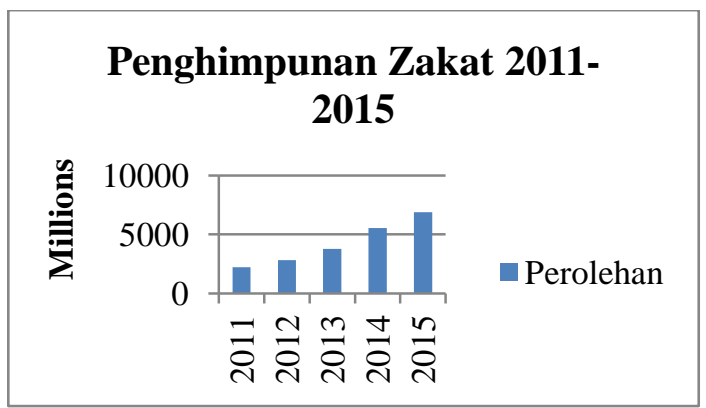

Gambar 1.

\section{Grafik Penghimpunan Zakat 2011-2015}

Dan dengan digalakkannya program zakat oleh SKPD Kabupaten Karanganyar, startegi ini dapat mencapai hasil yang diprogramkan setiap tahunnya. Sedangkan dalam pendistribusian, program yang telah dilakukan oleh BAZNAS Kabupaten Karanganyar tahun 2015 mencapai target sebagaimana ditampilkan pada tabel 1:24

Seperti yang telah diterangkan di atas oleh data-data yang didapatkan

23 Data diolah oleh penulis dengan rujukan Profil BAZNAS Kabupaten Karanganyar, hlm. 19

24 Tim BAZNAS Kabupaten Karanganyar, Laporan Kegiatan Tahun 2015, hlm. 26 oleh penulis, BAZNAS Karanganyar juga telah memiliki program-program dan strategi yang jitu dalam pendistribusian zakat untuk usaha produktif. Maka dari semua program-program penyaluran zakat produktif di BAZNAS Kabupaten Karanganyar, secara umum programprogram tersebut sudah distrategikan dengan baik sehingga taraf hidup masyarakat Kabupaten Karanganyar dapat ditingkatkan dan hal ini juga membantu masyarakat agar terbebas dari kemiskinan.

\section{KESIMPULAN DAN SARAN}

\section{Kesimpulan}

Dari uraian dan analisis di atas, penulis dapat mengambil kesimpulan sebagai berikut:

1. Strategi pengelolaan zakat produktif di BAZNAS Kabupaten Karanganyar memiliki dua kategori yaitu strategi pengumpulan dan pendistribusian sebagai berikut:

a. Strategi pengumpulan, yang mana dilakukan dengan pemotongan gaji para pegawai muslim di SKPD Kabupaten Karanganyar sebesar $2,5 \%$, layanan jemput zakat dan pembentukan UPZ (Unit Pengumpul 
Zakat) di beberapa desa dan masjid di Kabupaten Karanganyar.

b. Startegi pendistribusian, yang terprogram dalam program Karanganyar Makmur dengan rincian sebagai berikut:

1) Pengadaan Kursus-kursus dalam bidang komputer dan otomotif

2) Pelatihan industri menjahit tas

3) Pengembangan ternak kambing di beberapa desa Kabupaten Karanganyar

4) Pembiayaan para pedagang dan pengusaha kecil/PKL (Pedagang Kaki Lima)

5) Bantuan gaduh ternak sapi

6) Lain-lain dalam bentuk pembangunan unit usaha syariah dan Baitul Mal di beberapa kecamatan

2. Dari program-program yang telah diaplikasikan oleh BAZNAS Kabupaten Karanganyar, program-program tersebut dimaksudkan untuk meningkatkan taraf hidup para mustahik dari segi ekonomi, kemampuan dan moral sehingga kemiskinan dengan sebab apapun dapat diatasi.

\section{Saran}

Setelah melakukan penelitian dan analisis data, penulis bermaksud untuk memberikan beberapa saran untuk obyek penelitian. Dengan adanya saran ini, penulis mengharapkan saran ini menjadi kontribusi dan rekomendasi kepada pihak terkait. Adapun saran-saran tersebut adalah sebagai berikut:

1. Dalam meningkatkan potensi zakat produktif, maka pihak BAZNAS Kabupaten Karanganyar hendaknya lebih teliti dalam merealisasikan program-program yang berkenaan dengan zakat produktif.

2. Dan bagi para pihak mustahik agar lebih memperhatikan dan meningkatkan produktivitas harta zakat yang telah diberikan agar pengentasan kemiskinan dengan zakat produktif dapat terealisasikan.

\section{DAFTAR PUSTAKA}

Al-Ghazali (1994) Rahasia Puasa dan Zakat-Terjemahan oleh Muhammad Al-Baqir-(Bandung: Karisma)

Al-Qur'anul Karim

Amalia, Kasyful Mahali (2012), JurnalPotensi dan Peranan Zakat dalam Mengentaskan Kemiskinan di Kota Medan (Medan)

Departemen Agama (1993), Pedoman Zakat, (Jakarta: Proyek Pembinaan Zakat dan Wakaf)

Departemen Agama (1996) Pedoman Zakat 9 Seri (Jakarta: Departemen Agama)

DikutipolehK.H.DidinHafidhhuddin(2002)dal ambuku,ZakatDalamPerekonomia n Modern. (Jakarta: Gema Insani) Muhammad dan Ridwan Mas'ud (2005). Zakat dan Kemiskinan Instrumen Pemberdayaan Ekonomi Umat. (Yogyakarta: UII Press) 
Triyawan, et al/Jurnal Ekonomi Syariah Teori dan Terapan Vol. 6 No. 6 Juni 2019: 1304-1316; STATEGI PENGELOLAAN ZAKAT PRODUKTIF BADAN AMIL ZAKAT KABUPATEN KARANGANYAR DALAM RANGKA PENGENTASAN KEMISKINAN

Profil BAZNAS Kabupaten Karanganyar

Qadir, Abduracchman (2001)Zakat Dalam

Dimensi Mahdah dan Sosial.Cet.2

(Jakarta: PT. Raja Grafindo

Persada)

Ridwan Mas'ud dan Muhammad (2005)

Zakat dan Kemiskinan Instrumen

Pemberdayaan Ekonomi Umat

(Yogyakarta: UII Press)

Suara Merdeka, 26 April 2016, 10.36 WIB

Tim BAZNAS Kabupaten Karanganyar,

Laporan Kegiatan Tahun 2015
Transkip

Wawancara,

002/WWCR/AGUNGSYARIAH/IV/20 16

Transkrip

Wawancara,

001/WWCR/BAZNAS/IV/2016

Wahbah Az-Zuhayly (1995) Zakat Kajian Berbagai Mazhab (Bandung: PT Remaja Rosda Karya)

www.baznaskaranganyar.com

www.karanganyarkab.bps.go.id 